${ }^{1}$ Department of Diabetology and Internal Medicine, Medical University of Warsaw, Poland

${ }^{2}$ Department of Internal Diseases and Diabetology, Poznan University of Medical Sciences, Poland

${ }^{3}$ Institute of Healthcare Management, Lazarski University, Warsaw, Poland

${ }^{4}$ Department of Children's Diabetology, Medical University of Silesia, Poland

${ }^{5}$ Department of Metabolic Diseases Collegium Medicum, Jagiellonian University, Krakow, Poland

${ }^{6}$ Department of Pediatrics, Diabetology, Endocrinology and Nephrology, Medical University of Lodz, Poland

${ }^{7}$ Department of Pediatrics, Diabetology and Endocrinology, Medical University of Gdansk, Poland

${ }^{8}$ Department of Pediatrics, Medical University of Warsaw, Poland

${ }^{9}$ University Clinical Center, Medical University of Gdansk, Poland

\title{
Insulin pump therapy and continuous systems use in adult type 1 diabetes patients - Experts' Opinion
}

In the $21^{\text {st }}$ century, technological progress changed the therapy of patients with type 1 diabetes. Modern personal insulin pumps, and most of all continuous glucose monitoring (CGM) systems, improve the safety and comfort of life of patients with diabetes who require insulin administration. Insulin therapy with the use of CGM enables achieving a glycemic goal close to normoglycemia without an increased risk of hypoglycemia and, above all, prevents chronic complications of diabetes. This is especially important for people who are unaware of hypoglycaemia.

The reimbursement of the continuous glucose monitoring system in children and young adults $<26$ years of age treated with continuous subcutaneous insulin infusion (CSII) with the use of a personal insulin pump has increased the availability of new technologies improving the safety and effectiveness of insulin therapy for patients with type 1 diabetes in Poland. The

Address for correspondence:

dr hab. n. med., prof. nadzw. Leszek Czupryniak

Klinika Diabetologii i Chorób Wewnętrznych

Warszawski Uniwersytet Medyczny

ul. Banacha 1a, 02-097 Warszawa

e-mail: leszek.czupryniak@wum.edu.pl

Translation: lek. Małgorzata Kamińska

Clinical Diabetology 2020, 9, 4, 267-268

DOI: $10.5603 /$ DK.2020.0027

Received: 18.07.2020

Accepted: 18.07.2020 community of diabetes health care professionals is concerned about the fact that there is no reimbursement for adults older than 26 years of age, and particularly worrying are situations when, due to the discontinuation of reimbursement, a patient with impaired hypoglycemia awareness is deprived of a therapy that provides safety in terms of health and life and improves the quality of life. With the benefit of the patient and broadly understood social welfare in mind, we have developed the Healthcare Provision Charter "Real-Time Continuous Glucose Monitoring System (RT-CGM) in adults over 26 years of age with type 1 diabetes and hypoglycemia unawareness (i.e. the lack of prodromal symptoms of hypoglycemia) who are treated with an insulin pump". This document is the basis for starting a process aimed at reimbursing continuous glucose monitoring in patients over 26 years of age. We trust that this action, which is in line with the recent decisions of the Ministry of Health that are beneficial for diabetic patients, will become another good investment in health of Poles.

There is a consensus of opinions that the extension of CGM reimbursement will contribute to the improvement of the quality of care for patients with diabetes in Poland. A key element of qualitative changes would be guaranteed patient education services aimed at providing the patient with knowledge and skills to independently operate the CGM system, correctly calibrate 
it, interpret the direction and rate of changes in blood glucose (glycemic trends), respond to changing blood glucose values and program alarms.

Weighing the needs and opportunities, we included in the Healthcare Provision Charter adults with type 1 diabetes and impaired hypoglycemia awareness who have used insulin pump for 12 months in the last 18 months. This Expert Consensus Statement expresses special concern for adult patients with type 1 diabetes who are living with this disease for several dozen years and whose treatment with new technologies is often conditioned by a good economic status and ability to incur costs related to the use of CGM.

Clinical benefits of providing access to the CGM system and education in the use of the CGM system in adults with type 1 diabetes include the reduction of hypoglycemia and hyperglycemia episodes (which means more time spent in the glycemic target range), better quality of life and, above all, reduced risk of development and progression of acute and chronic diabetes complications. It is particularly important to reduce the frequency of severe hypoglycemia, which is a life threatening condition. Decreased rate of hypoglycemia will also contribute to the reduction of costs related to hospitalization, absenteeism and presenteeism in the workplace.

This technology not only improves the quality of diabetes care and increases the safety of insulin therapy, but also allows communication, analysis and conclusions, making e-counseling very effective. It turned out that the use of CGM and innovative telemedicine technology is possible and especially helpful for patients during the COVID-19 pandemic.

The position statement on the monitoring and treatment of type 1 diabetes in adult patients with the use of insulin pumps and a continuous glycemic monitoring system is in line with the social need and the creation of modern healthcare involving telemedicine. In the face of the global COVID-19 pandemic, the value of technologies allowing for monitoring and assessing patients from a distance is even more apparent.
Our opinion is consistent with the 2020 Guidelines on the management of diabetic patients. A position of Diabetes Poland which indicates therapeutic goals for diabetes treatment based on the use of continuous glucose monitoring systems. These guidelines also emphasize the importance of telemedicine in optimizing diabetes control.

The community of diabetes health care professionals appreciates the steps taken by the Ministry of Health to improve the quality of treatment for diabetics in Poland. Diabetes was on the list of national health priorities defined by the regulation of the Minister of Health of February 27, 2018, next to cardiovascular diseases, cancer and respiratory diseases [1]. This priority should be realized through education and increasing access of patients to diagnostic tools and methods of monitoring the progress and effects of diabetes therapy. In 2018-2020, the decisions of the Ministry of Health led to a significant improvement in the access of patients with diabetes to publicly reimbursed medical technologies and drugs.

Telephone consultations, remote blood glucose monitoring (e.g. using RT-CGM) and video consultations are the most frequently studied telemedicine interventions, each of them leading to increased access to specialist diabetes care. Unlike in cardiology, in diabetology, telemedicine solutions are rarely used in the healthcare system, despite the fact that, according to clinical trials, they translate into improved glycemic control and even reduced the risk of hypoglycaemia [2].

Increasing the availability of continuous glucose monitoring systems and relevant education in the use of CGM for patients with diabetes aged > 26 years who are treated with a personal insulin pump would constitute another positive breakthrough in diabetes care in our country.

\section{REFERENCES}

1. Rozporządzenie Ministra Zdrowia z dnia 27 lutego 2018 r. w sprawie priorytetów zdrowotnych Dostępne: http://www. dziennikustaw.gov.pl/du/2018/469.

2. Długaszek M, Gumprecht J, Berdzik-Kalarus S, et al. Telemedicine in response to challenges of modern diabetology. Clin Diabetol. 2016; 5(1): 22-25, doi: 10.5603/dk.2016.0004. 